Review Article

\title{
Sleep as a Mediator in the Pathway Linking Environmental Factors to Hypertension: A Review of the Literature
}

\author{
Oluwaseun A. Akinseye, ${ }^{1}$ Stephen K. Williams, ${ }^{2}$ \\ Azizi Seixas, ${ }^{2}$ Seithikurippu R. Pandi-Perumal, ${ }^{2}$ Julian Vallon, \\ Ferdinand Zizi, ${ }^{2}$ and Girardin Jean-Louis ${ }^{2}$ \\ ${ }^{1}$ Department of Medicine, Icahn School of Medicine at Mount Sinai, Queens Hospital Center, 82-68 164th Street, \\ Jamaica, NY 11432, USA \\ ${ }^{2}$ Center for Healthful Behavior Change, Department of Population Health, NYU School of Medicine, 227 East 30th Street, \\ New York, NY 10016, USA
}

Correspondence should be addressed to Girardin Jean-Louis; girardin.jean-louis@nyumc.org

Received 23 December 2014; Revised 20 February 2015; Accepted 20 February 2015

Academic Editor: Tomohiro Katsuya

Copyright (C) 2015 Oluwaseun A. Akinseye et al. This is an open access article distributed under the Creative Commons Attribution License, which permits unrestricted use, distribution, and reproduction in any medium, provided the original work is properly cited.

\begin{abstract}
Environmental factors, such as noise exposure and air pollution, are associated with hypertension. These environmental factors also affect sleep quality. Given the growing evidence linking sleep quality with hypertension, the purpose of this review is to investigate the role of sleep as a key mediator in the association between hypertension and environmental factors. Through this narrative review of the extant literature, we highlight that poor sleep quality mediates the relationship between environmental factors and hypertension. The conceptual model proposed in this review offers opportunities to address healthcare disparities in hypertension among African Americans by highlighting the disparate impact that the predictors (environmental factors) and mediator (sleep) have on the African-American community. Understanding the impact of these factors is crucial since the main outcome variable (hypertension) severely burdens the African-American community.
\end{abstract}

\section{Introduction}

Chronic noise exposure and air pollution have become a significant public health issue given its ubiquity in urban environments $[1,2]$. For the first time in history, more than $50 \%$ of the world's population lives in an urban environment, and it is estimated that it will likely rise to $70 \%$ by 2050 [1]. Urban environments teeming with subways, airplanes, road traffic, and emergency vehicle sirens are epicenters of chronic noise and pollutant exposure [3]. The health implications of chronic exposure to noise and pollutants are becoming more evident based on increased levels of related chronic disease, deaths, and impaired quality of life issues in urban populations. Noise complaints in New York City (NYC) were the primary insult to quality of life in the late 90s [4]. It is estimated that air pollution is responsible for $6 \%$ of annual deaths in NYC [5].

Although the association between hypertension and environmental factors, such as ambient noise exposure [6] and air pollutants $[7,8]$, is well documented primarily in laboratorybased studies [9-12], field-based studies accounting for chronic exposures will likely provide more clinically and ecologically relevant hypertension risk factors. Hypertension has a multifactorial etiology [13] and sleep quality has been identified as a factor associated with hypertension [14-17]. Hypertension and sleep disorders are common in the USA. It is estimated that 60-70 million Americans suffer from hypertension [18] and a similar number of Americans also suffer from chronic inadequate sleep, hindering daily functioning and adversely affecting health and longevity [19].

The theory that sleep could be a mediator in the role between environmental factors and cardiovascular health outcomes has been proposed in the past [20]. As per the Baron and Kenny model [21], to satisfy the conceptual model for mediating a predictor-outcome relationship, the following relationships must be present: (1) The proposed environmental factors (predictor variables) are significantly 


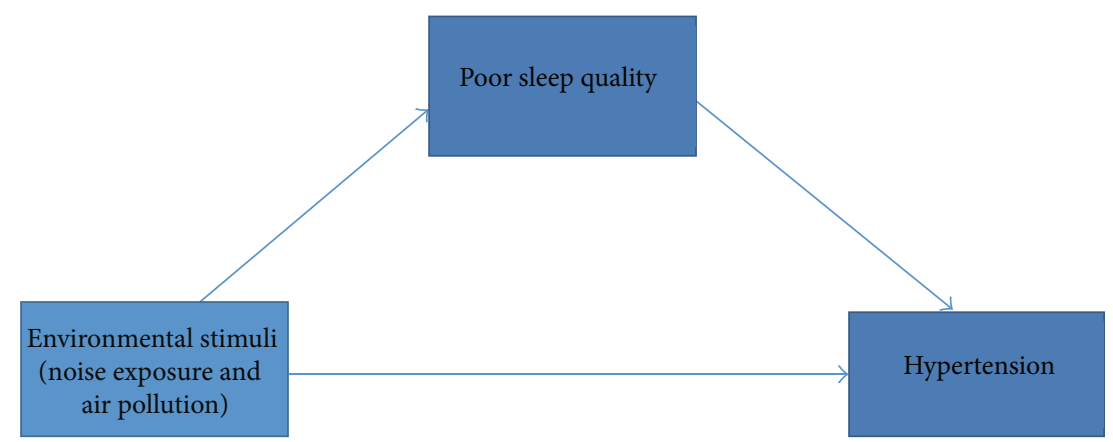

FIGURE 1: Conceptual model proposing sleep quality as a mediator in the pathway linking environmental stimuli to hypertension.

associated with hypertension (outcome variable); (2) the environmental factors must be significantly associated with sleep (mediating variable); and (3) sleep must be associated with hypertension (Figure 1). In a previous study, noise sensitivity and health complaints were noted to be associated and sleep was found to be a mediating variable [22]. Additionally, noisy neighborhoods were associated with lower self-rated physical health and the association was also mediated by sleep [23]. Conversely, in a study evaluating the adverse impact of night-time aircraft noise on endothelial function, sleep quality was not noted to be a mediating factor [24].

The purpose of this review is to summarize: (1) the relationship of hypertension to noise and air pollutants; (2) the relationship between sleep and the aforementioned environmental factors; and (3) the relationship between hypertension and sleep. We propose that relationships between these environmental factors and hypertension among Blacks would be especially relevant clinically because of the greater exposure to the aforementioned environmental factors as well as the greater prevalence of poor sleep quality in that population.

\section{Sleep and Hypertension}

Sleep has become of great interest in the field of hypertension because of the potential interventions that could be administered with resultant improvement in hypertension and its related adverse outcomes. The CARDIA Sleep Study, a longitudinal study examining the association between hypertension and sleep quality, showed an increase in the odds of hypertension among individuals with shorter sleep duration [25]. Data from a cross-sectional analysis of the 2009 National Health Interview Survey (NHIS) showed a higher likelihood of hypertension among individuals who reported daily sleep durations of 6 hours or less [26]. This is consistent with findings from the National Health and Nutrition Examination Survey (NHANES) I Epidemiologic Follow-Up Study that revealed a hazard ratio of 1.60 (95\% CI: 1.19, 2.14) for developing hypertension over 8 to 10 years among individuals reporting sleep duration of 5 hours or less compared with those sleeping 7 to 8 hours [15].

\section{Environmental Factors and Hypertension}

Environmental factors are included under the social determinants of health and are emphasized in the Healthy People
2020 initiative [27]. The environmental factors that this review will emphasize are limited to chronic ambient noise exposure (nonoccupational) and chronic ambient air pollution (Table 1). The air pollutants that will be discussed are predominantly $\mathrm{PM}_{2.5}$, which is defined as fine particulate matter $<2.5 \mu \mathrm{m}$ in diameter.

\section{Noise and Hypertension}

"Noise is generally defined as unwanted sound or set of sounds." [28] Noise disturbance is one of the most frequent complaints among urban-dwelling populations [28] and can be due to amplification of the noise levels by reflections off rigid urban area structures [29]. These areas are also more likely to have higher volume of vehicular traffic, train tracks, and airports [30]. Chronic exposure to subway traffic noise in New York City has been documented to have potential for significant adverse health effects with decibel levels exceeding $100 \mathrm{~dB}(\mathrm{~A})[30,31]$. Decibel levels $>70 \mathrm{~dB}(\mathrm{~A})$ are thought to be associated with harmful cardiovascular health effects [32].

The epidemiologic evidence associating noise with higher risk of developing hypertension continues to grow [3335]. The Hypertension and Exposure to Noise near Airport (HYENA) study, comprising almost 5,000 participants living close to several European airports, showed a significant exposure-response relationship between night-time aircraft, average daily road traffic noise exposure, and risk of hypertension [36]. Evidence shows a 1.14 (95\% CI: 1.01, 1.29) increase in the odds of developing hypertension with each $10 \mathrm{~dB}$ increase in exposure to night-time aircraft noise, and similar exposureresponse relationships were seen for road traffic noise in the highest exposure category of $>65 \mathrm{~dB}$ with a significant odds ratio (OR) of 1.54 (95\% CI: 0.99, 2.40) [36]. Furthermore, an increase of $0.26 \mathrm{mmHg}$ in systolic blood pressure (BP) per $10 \mathrm{~dB}$ increase in road traffic noise levels and a $8 \%$ higher risk of hypertension with exposure to railway noise $>60 \mathrm{~dB}$ were reported in another study [37]. A smaller study found that there were a 1.06 to 1.80 increased odds of hypertension for every $5 \mathrm{~dB}$ increase in noise exposure and the association was stronger among those who had lived at the same address for $>10$ years [38], suggesting additional impact among those with more chronic exposure. This finding was supported by another cross-sectional study that showed a stronger estimate of noise effect on the risk of hypertension in individuals with 


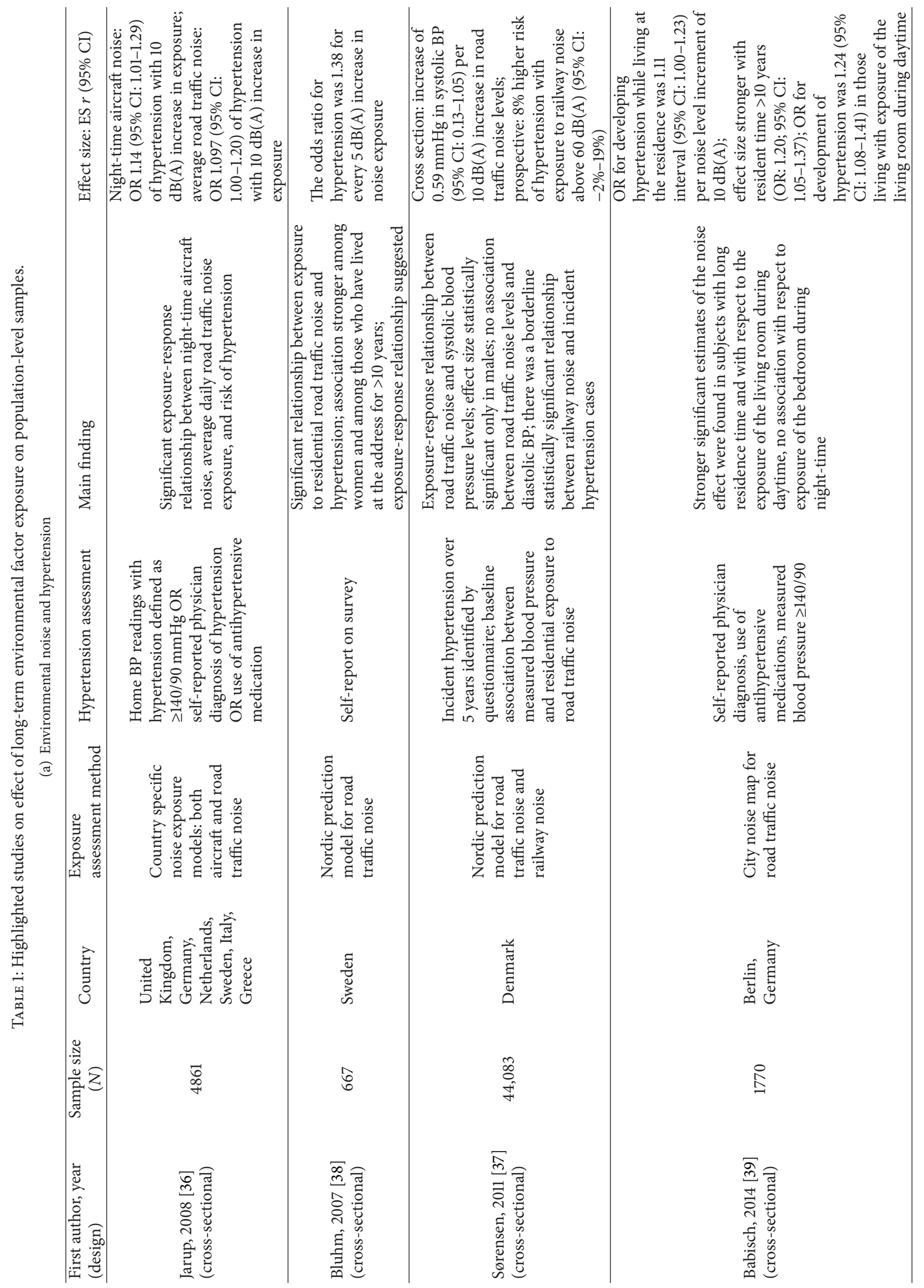




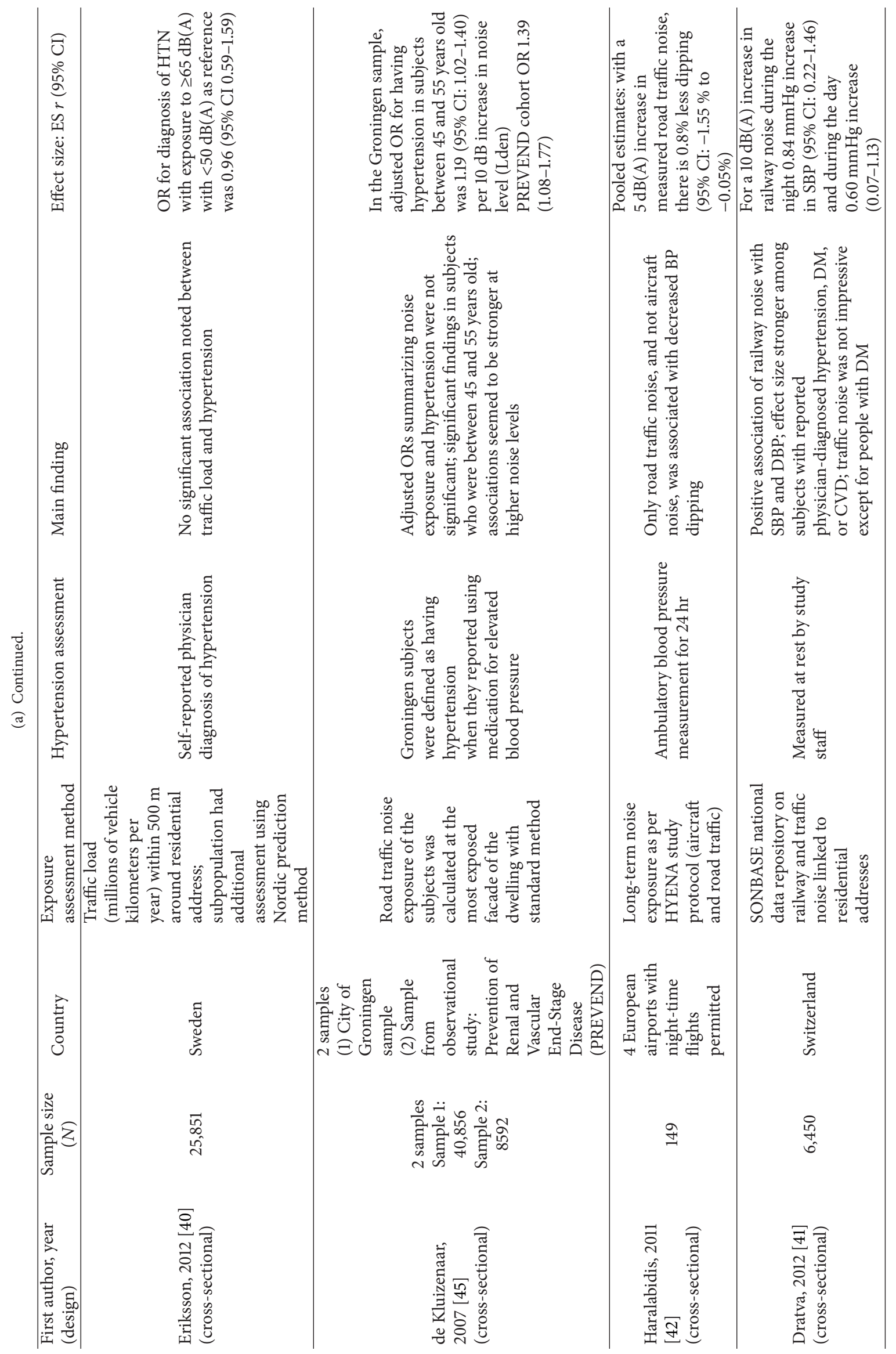




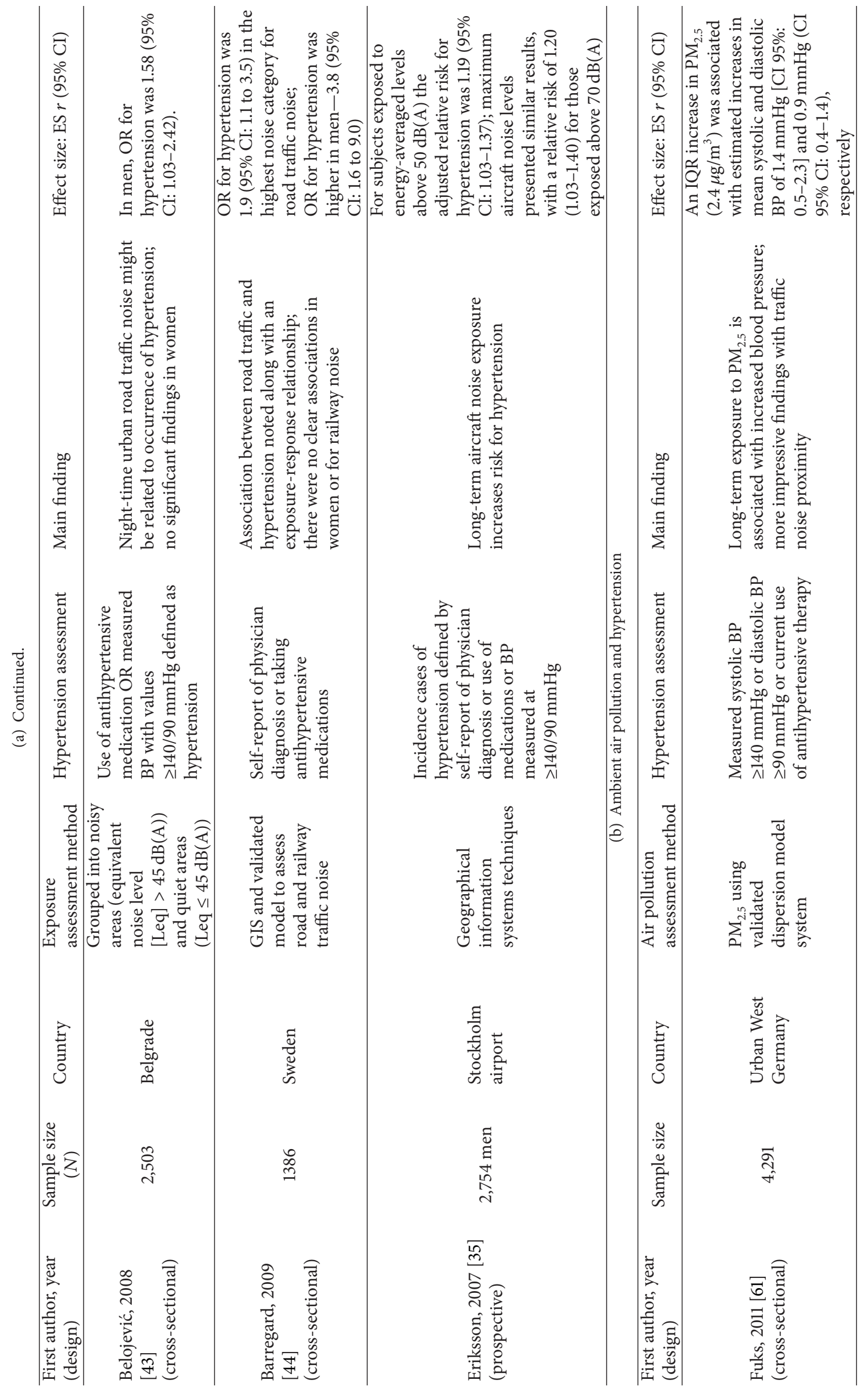




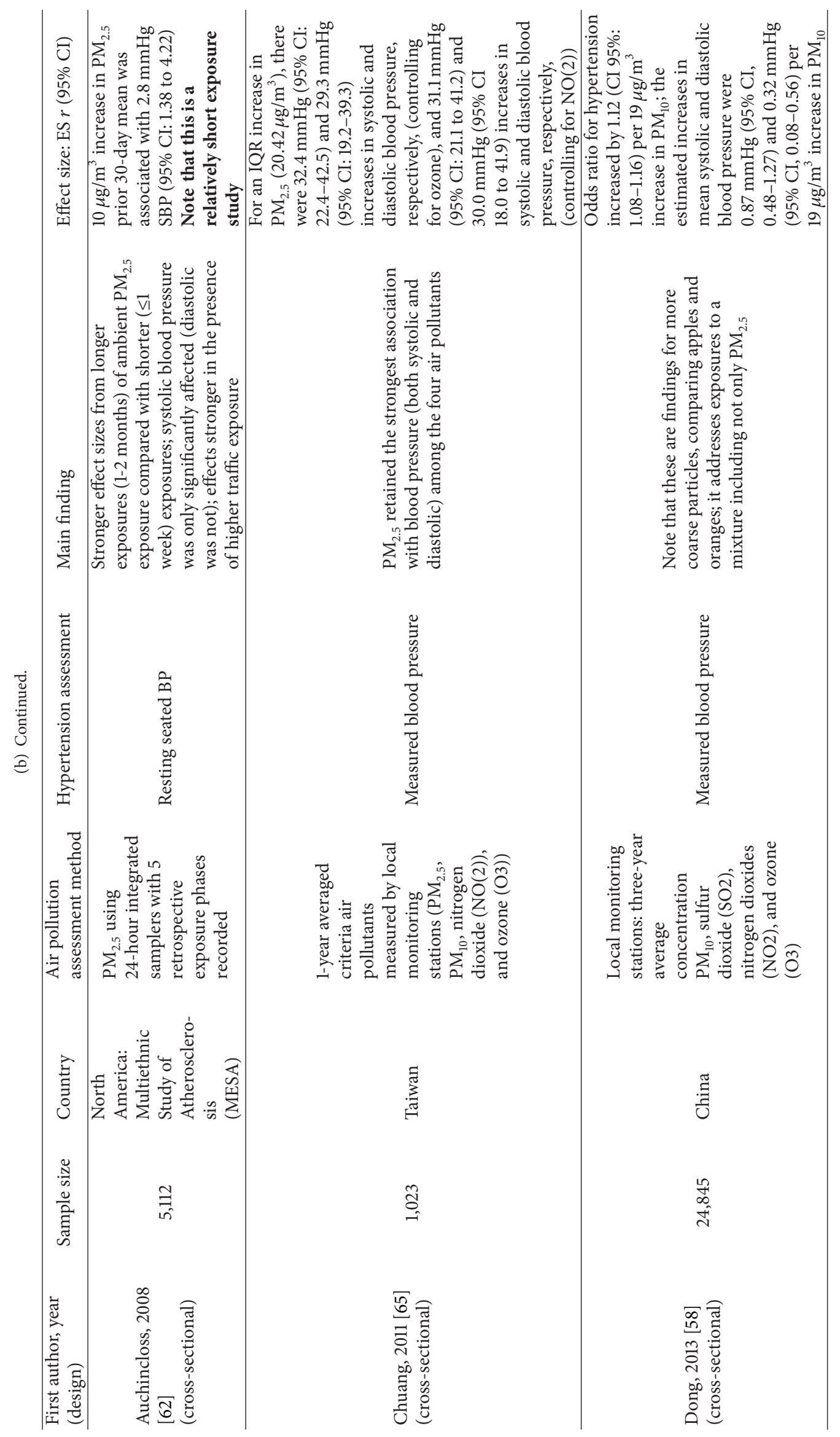




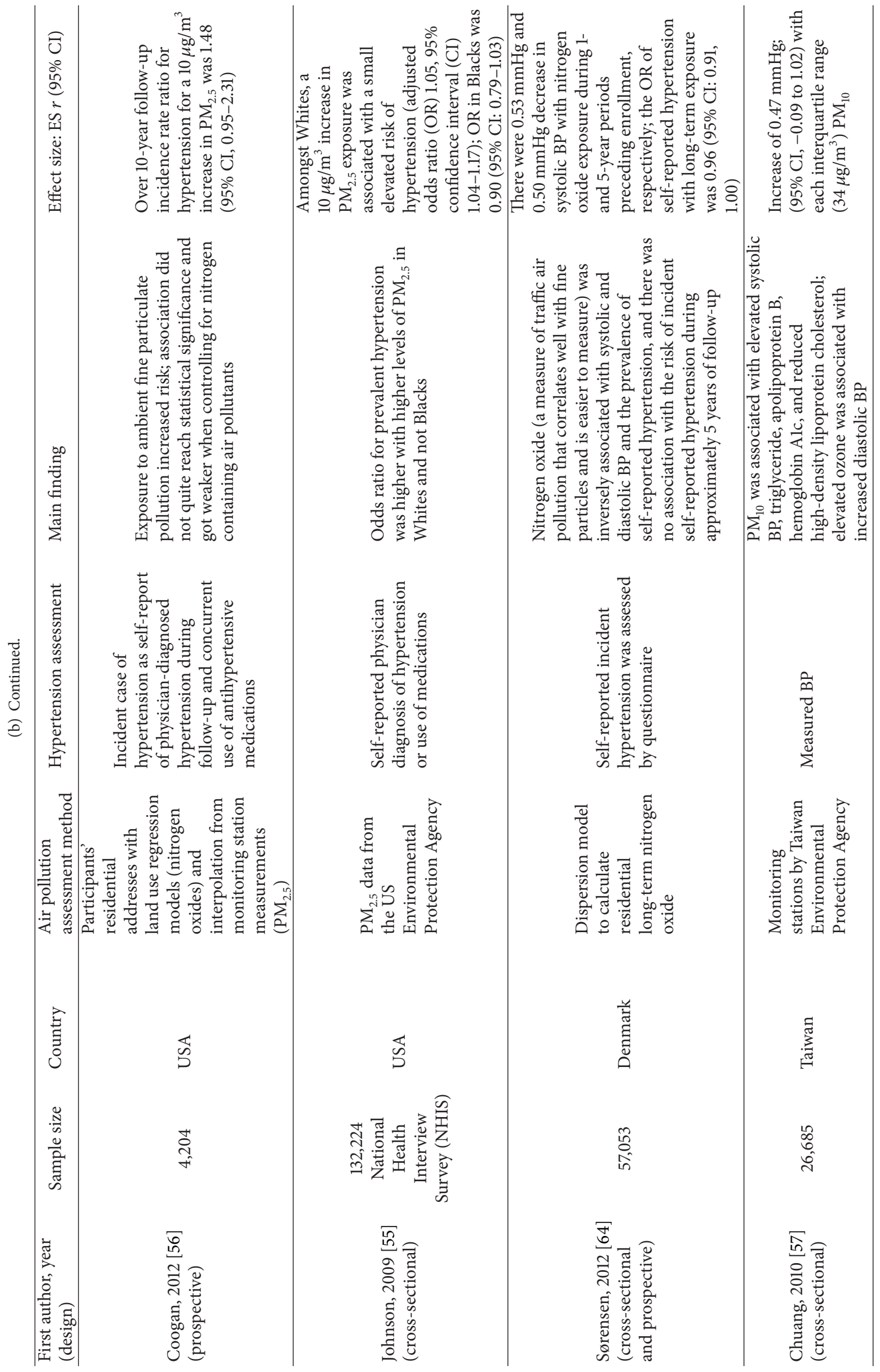




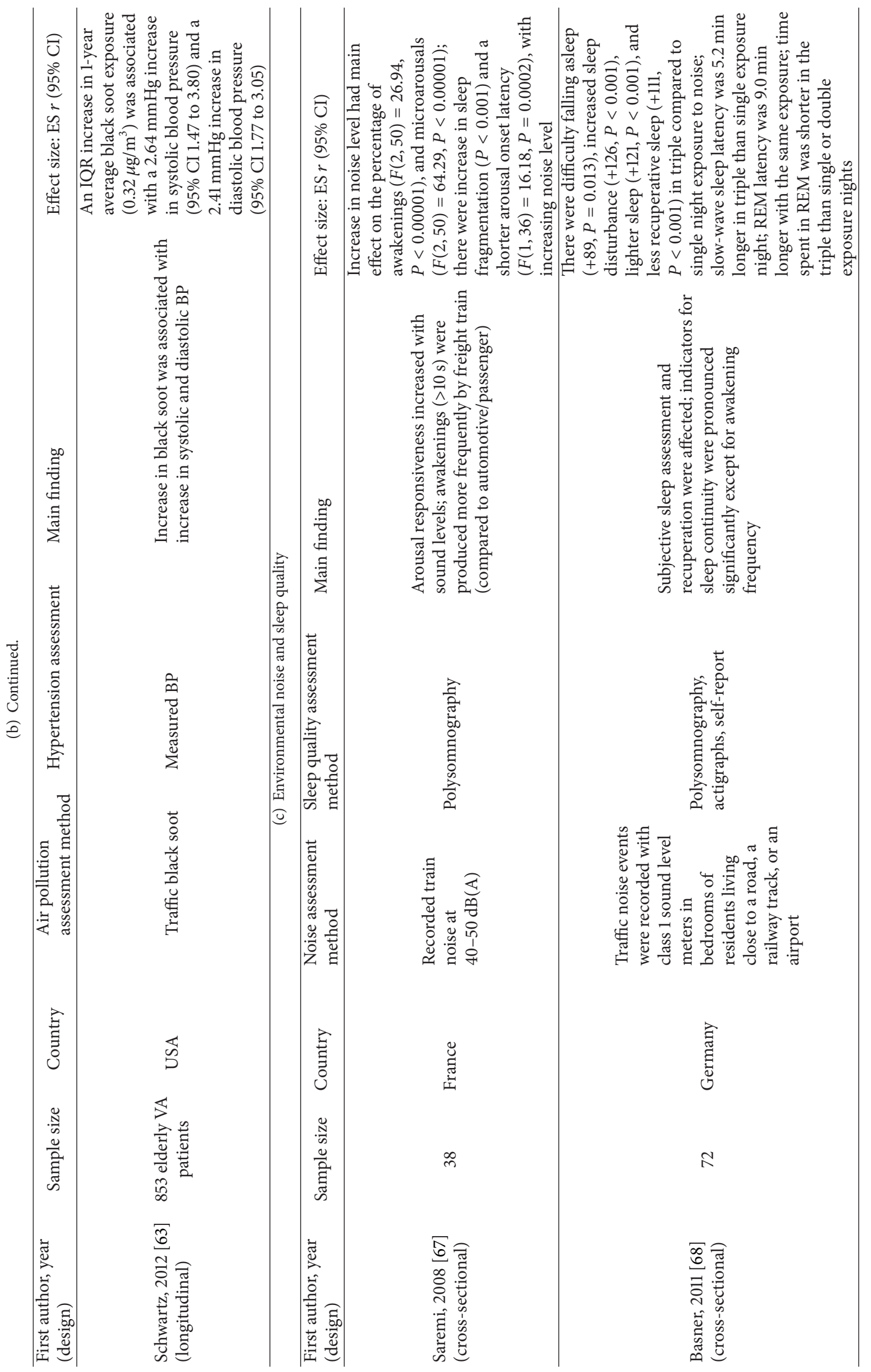




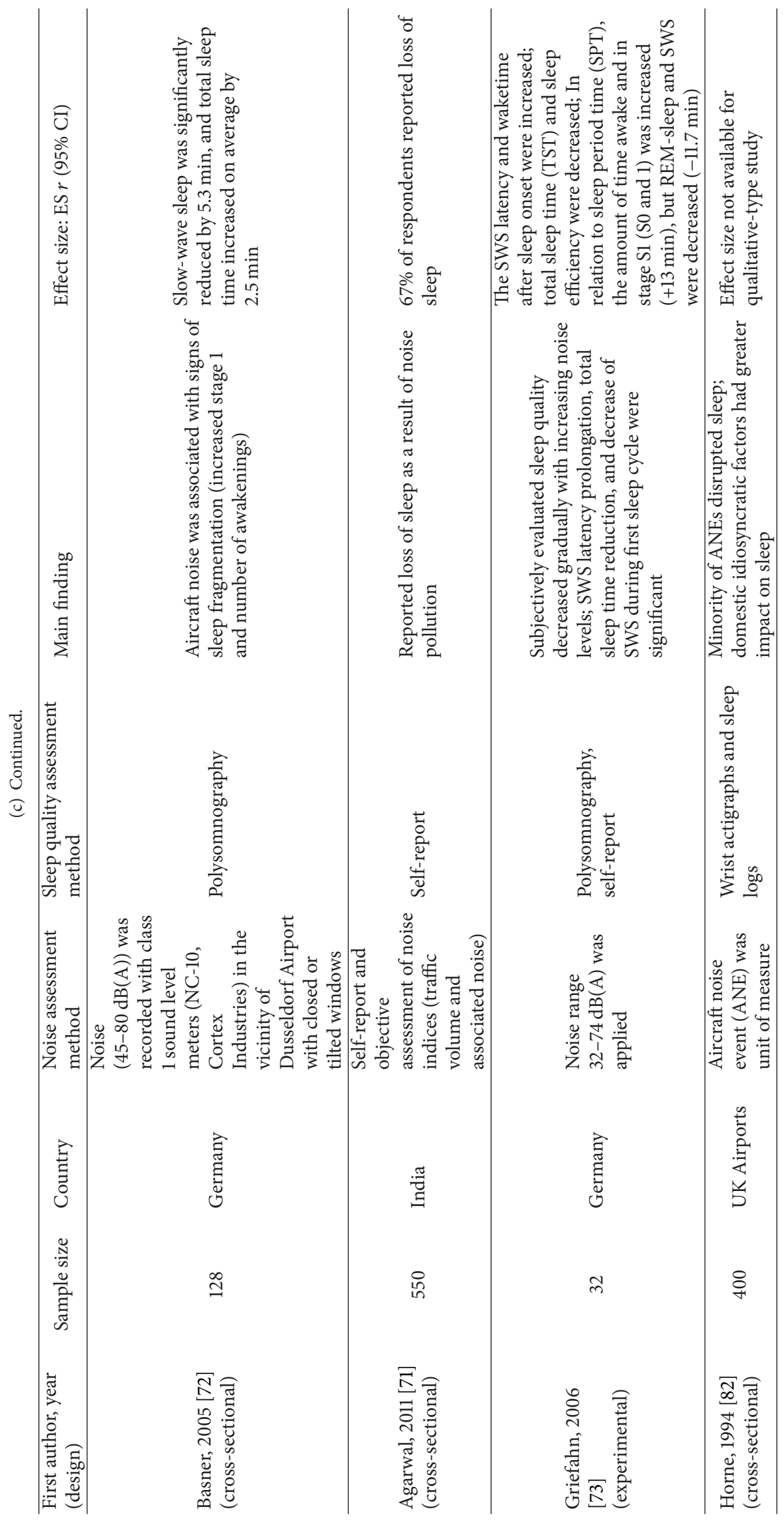




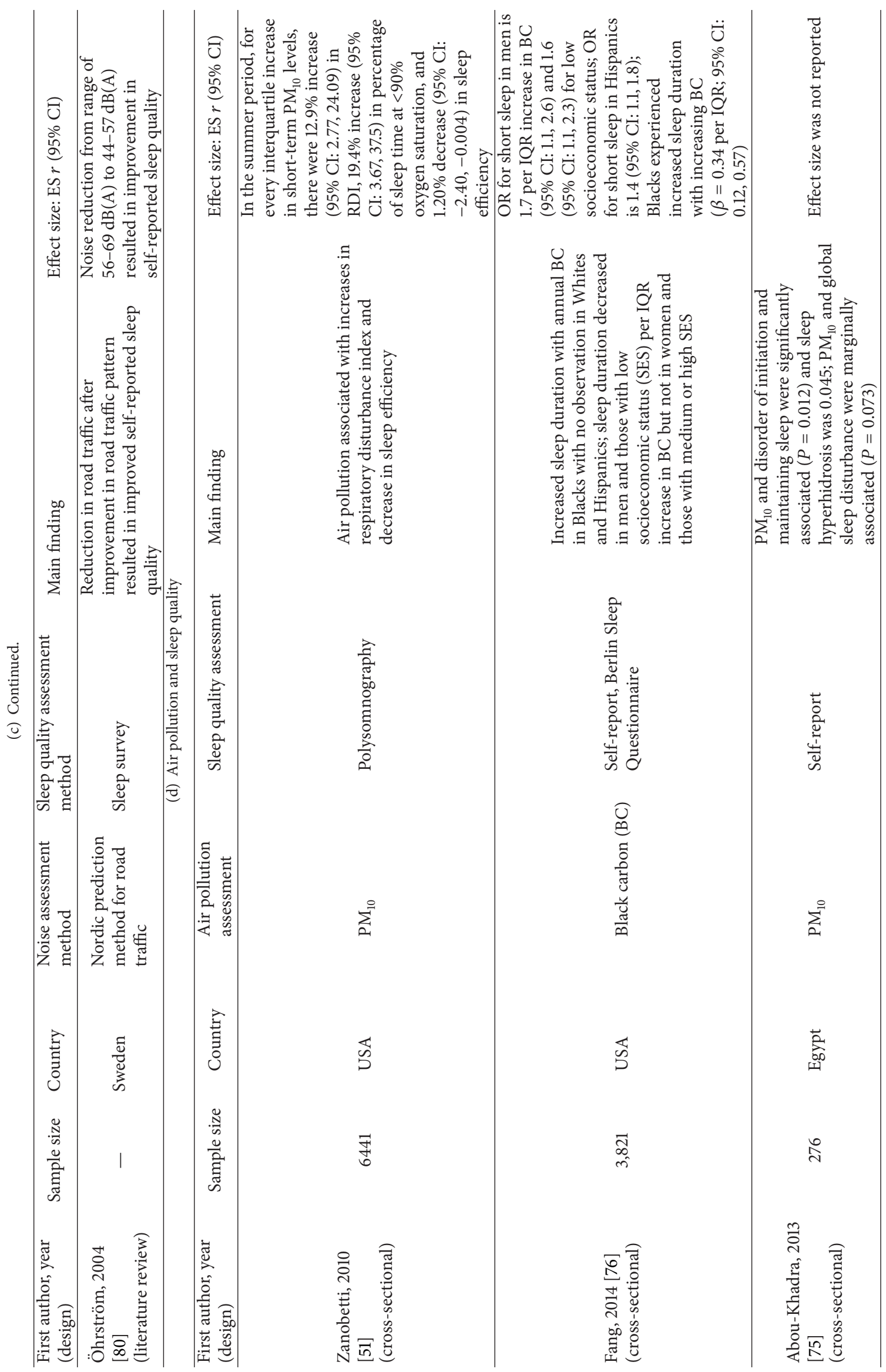


chronic noise exposure [39]. More significant estimates of the noise effect were found in subjects with long residence time (OR: 1.20, 95\% CI: 1.05-1.37) and with exposure of the living room during daytime (OR 1.24, 95\% CI: 1.08-1.41) compared with the exposure of the bedroom during night-time [39].

In contrast, the ROADSIDE study found no statistically significant association between road traffic noise and traffic load and self-reported hypertension [40]. This finding was reproduced by Dratva et al. [41], who showed no significant association between traffic noise and hypertension except in diabetics. Analysis of the HYENA study also supported this differential effect of the source of noise on hypertension [42]. Other studies found the association between noise and hypertension to be gender $[43,44]$ and age [45] dependent.

\section{Air Pollution and Hypertension}

The urbanization of most American cities is likely to worsen the problem of air pollution. In addition to soot, smog, smoke, dust, ozone, sulfur, carbon monoxide, nitrogen dioxide, and lead which make up the particulates, suspended particulates in the air come from increased combustion of motor vehicle fuel in the urbanized environment, posing a serious health threat among urban dwellers. Recommended limits for $\mathrm{PM}_{2.5}$ are $35 \mu \mathrm{g} / \mathrm{m}^{3}$ daily and $15.0 \mu \mathrm{g} / \mathrm{m}^{3}$ annually [46]. In 2000 , the annual average in downtown NYC was $17.5 \mu \mathrm{g} / \mathrm{m}^{3}$ [47]. Both indoor and outdoor pollution have been associated with adverse effects on human health [48-54]. Even though asthma is typically the disease associated with air pollution, accumulating evidence suggests that hypertension is associated with air pollution [55-58].

Data from a meta-analysis suggested that blood pressure (BP) was positively related to $\mathrm{PM}_{2.5}$ exposure, resulting in an increase of $1.393 \mathrm{mmHg}$ and $0.895 \mathrm{mmHg}$ per $10 \mu \mathrm{g} / \mathrm{m}^{3}$ increase in $\mathrm{PM}_{2.5}$ exposure for systolic $\mathrm{BP}$ and diastolic $\mathrm{BP}$, respectively [41]. Further supporting a causal mechanism was the finding that, with long-term exposure, there was a stronger association with BP increase [2]. This is consistent with findings in another study that found a $2.8 \mathrm{mmHg}$, $2.7 \mathrm{mmHg}$, and $2.7 \mathrm{mmHg}$ increase in resting systolic, diastolic, and mean arterial BP, respectively, following exposure to mean $\mathrm{PM}_{2.5}$ level of $10.5 \mu \mathrm{g} / \mathrm{m}^{3}$ [59]. Dvonch et al. [60] also noted similar associations between $\mathrm{PM}_{2.5}$ and $\mathrm{BP}$, and larger effects were observed when urban location was controlled for in the analysis. An interquartile range (IQR) increase in $\mathrm{PM}_{2.5}\left(2.4 \mu \mathrm{g} / \mathrm{m}^{3}\right)$ was found to be associated with estimated increases in mean systolic and diastolic BP of $1.4 \mathrm{mmHg}$ and $0.9 \mathrm{mmHg}$, respectively [61], and stronger effect sizes from chronic exposure to ambient air pollution [62] and other air pollutants [63] have been reported. There are conflicting results with the finding that long-term exposure to traffic air pollution is inversely associated with systolic and diastolic BP and the prevalence of self-reported hypertension [64]; however it should be noted that there were differences in the method that traffic air pollution was assessed in this study. The fact that nitric oxide (NO), but not $\mathrm{PM}_{2.5}$, was assessed makes direct comparison with the majority of the traffic air pollution studies difficult. It is also worthy of note that
$\mathrm{PM}_{2.5}$ retained the strongest association with blood pressure (both systolic and diastolic) among four air pollutants (ozone $(\mathrm{O}(3))$, nitrogen dioxide $(\mathrm{NO}(2))$, sulfur dioxide, and carbon monoxide) in a recent study [65].

\section{Environmental Factors and Sleep Quality}

Urban communities are more likely than rural communities to have certain neighborhood characteristics (i.e., noise and air pollution) that affect sleep quality. The odds of having short sleep are highest for those who live in central city environments with over 1 million people compared with residents of more rural, nonmetropolitan environments even after adjusting for socioeconomic and health characteristics [66].

\section{Noise and Sleep Quality}

Noise is independently associated with reduced sleep quality $[67,68]$. Data from a cross-sectional study showed that residing in noisy area is associated with difficulties falling asleep, falling back to sleep, waking up at night, and having poor sleep quality [69]. In a related study, chronic exposure to loud noise over a year was strongly associated with poor sleep efficiency resulting in a decrease in total rapid eye movement time, none rapid eye movement time, slow-wave sleep time, sleep onset latency, and total sleep time [70]. A Norwegian study also developed a model that presented sleep disturbance as a mediator of the noise and poor health relationship. It is interesting that a phenomenon of "noise annoyance" was found to be a mediator factor suggesting that a vulnerable subset of the population was more likely to suffer from the adverse health effects of noise [20]. Different populations have been noted to rate different sources of noise population as being noxious $[68,71]$. Environmental noise elevates arousal levels and fragments sleep resulting in a redistribution of time spent in the different sleep stages [68], typically increasing wake and stage 1 sleep and decreasing slow-wave and REM sleep $[72,73]$. The method by which sleep quality is assessed must be considered in examining the research literature since it has been reported that subjective assessment of sleep quality after exposure to noise does not correlate well with objective findings $[68,74]$.

\section{Air Pollution and Sleep Quality}

Decreases in sleep efficiency have been associated with increases in short-term variation of particulate air matter less than $10 \mu \mathrm{m}$ in aerodynamic diameter [51]. An analysis of a cross-sectional study showed a statistically significant association between higher $\mathrm{PM}_{10}$ exposure and disorders of initiation and maintenance of sleep assessed by the Sleep Disturbance Scale for children questionnaire [75]. Exposure to black carbon (a marker of traffic-related air pollution) in urban Boston was associated with short sleep duration in men and in the lower socioeconomic (SES) population. However, the complexities in such analysis are highlighted by associations with longer sleep duration in Blacks, an association not found in Whites or Hispanics [76]. 


\section{Discussion}

Even though there is accumulating evidence on the association between hypertension and environmental factors such as air and noise pollution, there remains a significant gap in elucidating the mechanism of this association. In the USA, there is a paucity of published research that has examined the association between hypertension and environmental factors with most of the cited research originating from the Scandinavian countries. This finding is somewhat surprising given the urbanization of our nation's communities. Nonetheless, these environmental factors, in particular air pollution, have become a critical issue for the American Heart Association (AHA) [54]. Given the evidence that environment plays a significant role in determining blood pressure levels and hypertension prevalence, it is imperative that the United States derived data be gathered in the interest of the nation's public health $[77,78]$.

The proposed model presented in this review is simple by virtue of the paucity of data on the relationships. Field studies, as opposed to laboratory studies, are indicated to correlate long-term exposure to environmental factors to hypertension and sleep. There is evidence that sleep responses to noise in the field are different to laboratory exposure [79] likely because of physiological factors such as habituation [80] and behavioral factors such as subject self-selection for living in particular locations [81]. Idiosyncratic domestic stimuli, such as bed partner movement and children going to bathrooms, have been shown to be more influential on sleep patterns than road traffic or aircraft noise $[82,83]$. Future models will need to clarify the relative contributions of genetics to the environment-hypertension association.

The premise of this paper is that there is a glaring gap in extant literature investigating the mediating effect of sleep on the noise-BP association, given the well-established associations of noise-BP and noise-sleep. The HYENA study demonstrated a relationship between exposure to aircraft noise and hypertension with a stronger relationship noted with night-time exposure to noise as opposed to daytime [36]. The implication of these findings is that night-time noise disturbance may be more significant by virtue of sleep disturbance. In a separate study of exposure to aircraft noise, while greater perception of noise disturbance was associated with poorer subjective sleep quality, higher objective measures of noise were associated with higher BP levels [84]. There is even more of a paucity of clinical research when exploring the air pollution-BP and the air pollution-sleep association. An intriguing area of exploration is the common denominator of electroencephalography (EEG) arousals in both the pathogenesis of BP physiology and sleep architecture. It is well established that EEG findings are instrumental in describing sleep architecture [85]. EEG changes have been observed when individuals are exposed to air pollutants [86], and similarly EEG findings have been shown to precede changes in BP homeostasis [87]. These findings suggest a gap in our understanding of the associations between environmental factors and $\mathrm{BP}$, warranting further investigations.

In the United States, there is the opportunity to link data sets such as NHANES with validated spatiotemporal models or data such as the NYC community air survey (NYCCAS) to investigate cross-sectional associations of environmental factors and hypertension. Such endeavors are in the infancy of being funded by the National Institute of Health (NIH) [88]. This recently funded study uses a cohort from Black Women's Health Study to determine the incidence of hypertension and diabetes associated with $\mathrm{PM}_{2.5}$ while controlling for noise confounded using innovative modelling.

Finally, the proposed model has the potential to address ethnic/racial disparities in the field of hypertension. Innovative research methods from Southern California have illustrated the excess exposure to road traffic and its pollutants that minority populations experience $[89,90]$. The National Institute of Environmental Health Sciences is a branch of the $\mathrm{NIH}$ that has at its core mandate a stated mission to address environmental health disparities. There is a higher prevalence of hypertension in the African American population and African Americans disproportionately suffer from poor sleep quality, relative to other racial/ethnic groups [66, 91-94]. They also dwell predominantly in urban populations and are subjected to a unique array of intense and prolonged environmental stimuli. There should be opportunities for further funding from the NIH to address these relevant issues.

\section{Conclusions}

In summary, sleep as a mediator in the pathway of the relationship between environmental factors and hypertension is an intriguing model with promising avenues for therapeutic intervention. The factors comprising the conceptual model are especially common and small improvements in the proposed predictor and mediator variables could lead to significant improvements in the management of hypertension. In addition, the epidemiology of the discussed variables is such that they promise to address racial/ethnic disparities in hypertension.

\section{Conflict of Interests}

The authors have read the journal's policy and all authors declare that they have no proprietary, financial, professional, or any other personal interests of any nature or kind in any product or services and/or company that could be construed or considered to be a potential conflict of interests that might have influenced the views expressed in this paper.

\section{Authors' Contribution}

Oluwaseun A. Akinseye, Stephen K. Williams, Azizi Seixas, Ferdinand Zizi, and Girardin Jean-Louis conceived and designed the outline of review. Oluwaseun A. Akinseye, Stephen K. Williams, Seithikurippu R. Pandi-Perumal, Julian Vallon, and Girardin Jean-Louis performed the literature search. Oluwaseun A. Akinseye, Stephen K. Williams, Azizi Seixas, Seithikurippu R. Pandi-Perumal, and Girardin Jean-Louis wrote the paper. All authors approved the final version of the paper that was submitted for publication. 


\section{Acknowledgment}

This research was supported by funding from the National Institute of Health (U54NS081765, R01HL095799, and R01MD007716). However, the funders had no role in the preparation or decision to publish the paper.

\section{References}

[1] B. L. City and E. Assessment, "Urbanization and health," Bulletin of the World Health Organization, vol. 88, no. 4, pp. 245-246, 2010.

[2] S. Luzzi, "Urban noise management and its practical implementation," in Proceedings 20th International Congress on Sound and Vibration (ICSV20 '13), Bangkok, Thailand, July 2013.

[3] A. Skånberg and E. Öhrström, "Adverse health effects in relation to urban residential soundscapes," Journal of Sound and Vibration, vol. 250, no. 1, pp. 151-155, 2002.

[4] L. Goines and L. Hagler, "Noise pollution: a modern plague," Southern Medical Journal, vol. 100, no. 3, pp. 287-294, 2007.

[5] New York City Department of Environmental Protection, Air Pollution, New York City Environmental Protection Web site, 2014, http://www.nyc.gov/html/dep/html/air/index.shtml.

[6] E. van Kempen and W. Babisch, "The quantitative relationship between road traffic noise and hypertension: a meta-analysis," Journal of Hypertension, vol. 30, no. 6, pp. 1075-1086, 2012.

[7] R. Liang, B. Zhang, X. Zhao, Y. Ruan, H. Lian, and Z. Fan, "Effect of exposure to PM2.5 on blood pressure: a systematic review and meta-analysis," Journal of Hypertension, vol. 32, no. 11, pp. 21302141, 2014.

[8] R. D. Brook, "Why physicians who treat hypertension should know more about air pollution," The Journal of Clinical Hypertension, vol. 9, no. 8, pp. 629-635, 2007.

[9] L. Andren, "Cardiovascular effects of noise," Acta medica Scandinavica. Supplementum, vol. 657, pp. 1-45, 1982.

[10] L. Andren, L. Hansson, R. Eggertsen, T. Hedner, and B. E. Karlberg, "Circulatory effects of noise," Acta Medica Scandinavica, vol. 213, no. 1, pp. 31-35, 1983.

[11] L. Andrén, G. Lindstedt, M. Björkman, K. O. Borg, and L. Hansson, "Effect of noise on blood pressure and 'stress' hormones," Clinical Science, vol. 62, no. 2, pp. 137-141, 1982.

[12] B. Urch, F. Silverman, P. Corey et al., "Acute blood pressure responses in healthy adults during controlled air pollution exposures," Environmental Health Perspectives, vol. 113, no. 8, pp. 1052-1055, 2005.

[13] World Health Organization, A Global Brief on Hypertension: Silent Killer, Global Public Health Crisis: World Health Day 2013, 2013.

[14] J. Fang, A. G. Wheaton, N. L. Keenan, K. J. Greenlund, G. S. Perry, and J. B. Croft, "Association of sleep duration and hypertension among us adults varies by age and sex," The American Journal of Hypertension, vol. 25, no. 3, pp. 335-341, 2012.

[15] J. E. Gangwisch, S. B. Heymsfield, B. Boden-Albala et al., "Short sleep duration as a risk factor for hypertension: analyses of the first National Health and Nutrition Examination Survey," Hypertension, vol. 47, no. 5, pp. 833-839, 2006.

[16] L. Meng, Y. Zheng, and R. Hui, “The relationship of sleep duration and insomnia to risk of hypertension incidence: a metaanalysis of prospective cohort studies," Hypertension Research, vol. 36, no. 11, pp. 985-995, 2013.
[17] X. Guo, L. Zheng, J. Wang, X. Zhang, J. Li, and Y. Sun, "Epidemiological evidence for the link between sleep duration and high blood pressure: a systematic review and meta-analysis," Sleep Medicine, vol. 14, no. 4, pp. 324-332, 2013.

[18] Centers for Disease Control and Prevention (CDC), "Vital signs: awareness and treatment of uncontrolled hypertension among adults-United States, 2003-2010," Morbidity and Mortality Weekly Report, vol. 61, no. 35, pp. 703-709, 2012.

[19] H. Colten and B. Altevogt, Sleep Disorders and Sleep Deprivation, The National Academies Press, 2006.

[20] A. Fyhri and G. M. Aasvang, "Noise, sleep and poor health: modeling the relationship between road traffic noise and cardiovascular problems," Science of the Total Environment, vol. 408, no. 21, pp. 4935-4942, 2010.

[21] R. M. Baron and D. A. Kenny, "The moderator-mediator variable distinction in social psychological research: conceptual, strategic, and statistical considerations," Journal of Personality and Social Psychology, vol. 51, no. 6, pp. 1173-1182, 1986.

[22] E. M. Hill, R. Billington, and C. Krägeloh, "Noise sensitivity and diminished health: testing moderators and mediators of the relationship," Noise and Health, vol. 16, no. 68, pp. 47-56, 2014.

[23] L. Hale, T. D. Hill, and A. M. Burdette, "Does sleep quality mediate the association between neighborhood disorder and self-rated physical health?" Preventive Medicine, vol. 51, no. 34, pp. 275-278, 2010.

[24] F. Schmidt, K. Kolle, K. Kreuder et al., "Nighttime aircraft noise impairs endothelial function and increases blood pressure in patients with or at high risk for coronary artery disease," Clinical Research in Cardiology, vol. 104, no. 1, pp. 23-30, 2015.

[25] K. L. Knutson, E. van Cauter, P. J. Rathouz et al., "Association between sleep and blood pressure in midlife: the CARDIA sleep study," Archives of Internal Medicine, vol. 169, no. 11, pp. 10551061, 2009.

[26] A. Pandey, N. Williams, M. Donat et al., "Linking sleep to hypertension: greater risk for blacks," International Journal of Hypertension, vol. 2013, Article ID 436502, 7 pages, 2013.

[27] U.S. Department of Health and Human Services, Determinants of health, 2014, https://www.healthypeople.gov/2020/about/ foundation-health-measures/Determinants-of-Health.

[28] A. Muzet, "Environmental noise, sleep and health," Sleep Medicine Reviews, vol. 11, no. 2, pp. 135-142, 2007.

[29] T. van Renterghem and D. Botteldooren, "Focused study on the quiet side effect in dwellings highly exposed to road traffic noise," International Journal of Environmental Research and Public Health, vol. 9, no. 12, pp. 4292-4310, 2012.

[30] R. R. M. Gershon, R. Neitzel, M. A. Barrera, and M. Akram, "Pilot survey of subway and bus stop noise levels," Journal of Urban Health, vol. 83, no. 5, pp. 802-812, 2006.

[31] New York City Department of Environmental Protection, "Transit operations strategies, new york city noise code," Local law 113 of 2005, 2010, http://www.nyc.gov/, http://www.nyc.gov/ $\mathrm{html} / \mathrm{dep} / \mathrm{pdf} /$ noise/transit-noise-study.pdf.

[32] W. Passchier-Vermeer and W. F. Passchier, "Noise exposure and public health," Environmental Health Perspectives, vol. 108, supplement 1, pp. 123-131, 2000.

[33] T.-Y. Chang, R. Beelen, S.-F. Li et al., "Road traffic noise frequency and prevalent hypertension in Taichung, Taiwan: a cross-sectional study," Environmental Health, vol. 13, article 37, 2014.

[34] T.-Y. Chang, Y.-A. Lai, H.-H. Hsieh, J.-S. Lai, and C.-S. Liu, "Effects of environmental noise exposure on ambulatory blood 
pressure in young adults," Environmental Research, vol. 109, no. 7, pp. 900-905, 2009.

[35] C. Eriksson, M. Rosenlund, G. Pershagen, A. Hilding, C.G. Östenson, and G. Bluhm, "Aircraft noise and incidence of hypertension," Epidemiology, vol. 18, no. 6, pp. 716-721, 2007.

[36] L. Jarup, W. Babisch, D. Houthuijs et al., "Hypertension and exposure to noise near airports: the HYENA study," Environmental Health Perspectives, vol. 116, no. 3, pp. 329-333, 2008.

[37] M. Sørensen, M. Hvidberg, B. Hoffmann et al., "Exposure to road traffic and railway noise and associations with blood pressure and self-reported hypertension: a cohort study," Environmental Health, vol. 10, no. 1, article 92, 2011.

[38] G. L. Bluhm, N. Berglind, E. Nordling, and M. Rosenlund, "Road traffic noise and hypertension," Occupational and Environmental Medicine, vol. 64, no. 2, pp. 122-126, 2007.

[39] W. Babisch, G. Wölke, J. Heinrich, and W. Straff, "Road traffic noise and hypertension-accounting for the location of rooms," Environmental Research, vol. 133, pp. 380-387, 2014.

[40] C. Eriksson, M. E. Nilsson, S. M. Willers, L. Gidhagen, T. Bellander, and G. Pershagen, "Traffic noise and cardiovascular health in Sweden: the roadside study," Noise and Health, vol. 14, no. 59, pp. 140-147, 2012.

[41] J. Dratva, H. C. Phuleria, M. Foraster et al., "Transportation noise and blood pressure in a population-based sample of adults," Environmental Health Perspectives, vol. 120, no. 1, pp. 50-55, 2012.

[42] A. S. Haralabidis, K. Dimakopoulou, V. Velonaki et al., "Can exposure to noise affect the $24 \mathrm{~h}$ blood pressure profile? Results from the HYENA study," Journal of Epidemiology and Community Health, vol. 65, no. 6, pp. 535-541, 2011.

[43] G. A. Belojević, B. D. Jakovljević, V. J. Stojanov, V. Ž. Slepčević, and K. Ž. Paunović, "Nighttime road-traffic noise and arterial hypertension in an urban population," Hypertension Research, vol. 31, no. 4, pp. 775-781, 2008.

[44] L. Barregard, E. Bonde, and E. Öhrström, "Risk of hypertension from exposure to road traffic noise in a population-based sample," Occupational and Environmental Medicine, vol. 66, no. 6, pp. 410-415, 2009.

[45] Y. de Kluizenaar, R. T. Gansevoort, H. M. E. Miedema, and P. E. de Jong, "Hypertension and road traffic noise exposure," Journal of Occupational \& Environmental Medicine, vol. 49, no. 5, pp. 484-492, 2007.

[46] U.S. Environmental Protection Agency, National Ambient Air Quality Standards (NAAQS), 2011, http://www.epa.gov/, http:// www.epa.gov/air/criteria.html.

[47] New York State Department of Environmental Conservation, PM2.5 / PM10 monitoring data, 2011, http://www.dec.ny.gov/ chemical/8888.html.

[48] N. Canha, S. M. Almeida, M. C. Freitas, and H. T. Wolterbeek, "Indoor and outdoor biomonitoring using lichens at urban and rural primary schools," Journal of Toxicology and Environmental Health A, vol. 77, no. 14-16, pp. 900-915, 2014.

[49] A. Hajat, A. V. Diez-Roux, N. Jenny, A. Szpiro, and J. Kaufman, "Long-term exposure to air pollution and markers of inflammation, coagulation and endothelial activation: a repeat measures analysis in the multi-ethnic study of atherosclerosis," Circulation, vol. 129, supplement 1, p. AP243, 2014.

[50] D. L. DeMeo, A. Zanobetti, A. A. Litonjua, B. A. Coull, J. Schwartz, and D. R. Gold, "Ambient air pollution and oxygen saturation," The American Journal of Respiratory and Critical Care Medicine, vol. 170, no. 4, pp. 383-387, 2004.
[51] A. Zanobetti, S. Redline, J. Schwartz et al., "Associations of PM10 with sleep and sleep-disordered breathing in adults from seven U.S. urban areas," The American Journal of Respiratory and Critical Care Medicine, vol. 182, no. 6, pp. 819-825, 2010.

[52] H. Luttmann-Gibson, S. E. Sarnat, H. H. Suh et al., "Shortterm effects of air pollution on oxygen saturation in a cohort of senior adults in steubenville, Ohio," Journal of Occupational and Environmental Medicine, vol. 56, no. 2, pp. 149-154, 2014.

[53] P. L. Ljungman and M. A. Mittleman, "Ambient air pollution and stroke," Stroke, vol. 45, no. 12, pp. 3734-3741, 2014.

[54] R. D. Brook, S. Rajagopalan, C. A. Pope III et al., "Particulate matter air pollution and cardiovascular disease: an update to the scientific statement from the American Heart Association," Circulation, vol. 121, no. 21, pp. 2331-2378, 2010.

[55] D. Johnson and J. D. Parker, "Air pollution exposure and selfreported cardiovascular disease," Environmental Research, vol. 109, no. 5, pp. 582-589, 2009.

[56] P. F. Coogan, L. F. White, M. Jerrett et al., "Air pollution and incidence of hypertension and diabetes mellitus in black women living in Los Angeles," Circulation, vol. 125, no. 6, pp. 767-772, 2012.

[57] K. J. Chuang, Y. H. Yan, and T. J. Cheng, "Effect of air pollution on blood pressure, blood lipids, and blood sugar: a populationbased approach," Journal of Occupational and Environmental Medicine, vol. 52, no. 3, pp. 258-262, 2010.

[58] F. M. Dong, Y. Z. Mo, G. X. Li, M. M. Xu, and X. C. Pan, "Association between ambient $\mathrm{PM}_{10} / \mathrm{PM}_{2.5}$ levels and population mortality of circulatory diseases: a case-crossover study in Beijing," Beijing Da Xue Xue Bao, vol. 45, no. 3, pp. 398-404, 2013.

[59] A. Zanobetti, M. J. Canner, P. H. Stone et al., "Ambient pollution and blood pressure in cardiac rehabilitation patients," Circulation, vol. 110, no. 15, pp. 2184-2189, 2004.

[60] J. T. Dvonch, S. Kannan, A. J. Schulz et al., "Acute effects of ambient particulate matter on blood pressure: differential effects across urban communities," Hypertension, vol. 53, no. 5, pp. 853-859, 2009.

[61] K. Fuks, S. Moebus, S. Hertel et al., "Long-term urban particulate air pollution, traffic noise, and arterial blood pressure," Environmental Health Perspectives, vol. 119, no. 12, pp. 1706-1711, 2011.

[62] A. H. Auchincloss, A. V. Diez Roux, J. T. Dvonch et al., "Associations between recent exposure to ambient fine particulate matter and blood pressure in the multi-ethnic study of atherosclerosis (MESA)," Environmental Health Perspectives, vol. 116, no. 4, pp. 486-491, 2008.

[63] J. Schwartz, S. E. Alexeeff, I. Mordukhovich et al., "Association between long-term exposure to traffic particles and blood pressure in the veterans administration normative aging study," Occupational \& Environmental Medicine, vol. 69, no. 6, pp. 422427, 2012.

[64] M. Sørensen, B. Hoffmann, M. Hvidberg et al., "Long-term exposure to traffic-related air pollution associated with blood pressure and self-reported hypertension in a Danish Cohort," Environmental Health Perspectives, vol. 120, no. 3, pp. 418-424, 2012.

[65] K. J. Chuang, Y. H. Yan, S. Y. Chiu, and T. J. Cheng, "Longterm air pollution exposure and risk factors for cardiovascular diseases among the elderly in Taiwan," Occupational and Environmental Medicine, vol. 68, no. 1, pp. 64-68, 2011. 
[66] L. Hale and D. P. Do, "Racial differences in self-reports of sleep duration in a population-based study," Sleep, vol. 30, no. 9, pp. 1096-1103, 2007.

[67] M. Saremi, J. Grenèche, A. Bonnefond, O. Rohmer, A. Eschenlauer, and P. Tassi, "Effects of nocturnal railway noise on sleep fragmentation in young and middle-aged subjects as a function of type of train and sound level," International Journal of Psychophysiology, vol. 70, no. 3, pp. 184-191, 2008.

[68] M. Basner, U. Müller, and E.-M. Elmenhorst, "Single and combined effects of air, road, and rail traffic noise on sleep and recuperation," Sleep, vol. 34, no. 1, pp. 11-23, 2011.

[69] B. Jakovljević, G. Belojević, K. Paunović, and V. Stojanov, "Road traffic noise and sleep disturbances in an urban population: cross-sectional study," Croatian Medical Journal, vol. 47, no. 1, pp. 125-133, 2006.

[70] B. Gitanjali and R. Dhamotharan, "Effect of occupational noise on the nocturnal sleep architecture of healthy subjects," Indian Journal of Physiology and Pharmacology, vol. 47, no. 4, pp. 415422, 2003.

[71] S. Agarwal and B. L. Swami, "Road traffic noise, annoyance and community health survey - a case study for an Indian city," Noise and Health, vol. 13, no. 53, pp. 272-276, 2011.

[72] M. Basner and A. Samel, "Effects of nocturnal aircraft noise on sleep structure," Somnologie, vol. 9, no. 2, pp. 84-95, 2005.

[73] B. Griefahn, A. Marks, and S. Robens, "Noise emitted from road, rail and air traffic and their effects on sleep," Journal of Sound and Vibration, vol. 295, no. 1-2, pp. 129-140, 2006.

[74] S. Pirrera, E. de Valck, and R. Cluydts, "Field study on the impact of nocturnal road traffic noise on sleep: the importance of in- and outdoor noise assessment, the bedroom location and nighttime noise disturbances," Science of the Total Environment, vol. 500-501, pp. 84-90, 2014.

[75] M. K. Abou-Khadra, "Association between PM10 exposure and sleep of Egyptian school children," Sleep and Breathing, vol. 17, no. 2, pp. 653-657, 2013.

[76] S. C. Fang, J. Schwartz, M. Yang, H. K. Yaggi, D. L. Bliwise, and A. B. Araujo, "Traffic-related air pollution and sleep in the Boston area community health survey," Journal of Exposure Science and Environmental Epidemiology, 2014.

[77] K. Wolf-Maier, R. S. Cooper, J. R. Banegas et al., "Hypertension prevalence and blood pressure levels in 6 European countries, Canada, and the United States," The Journal of the American Medical Association, vol. 289, no. 18, pp. 2363-2369, 2003.

[78] T. A. Kotchen and J. M. Kotchen, "Regional variations of blood pressure: environment or genes?” Circulation, vol. 96, no. 4, pp. 1071-1073, 1997.

[79] S. Fidell, K. Pearsons, B. Tabachnick, R. Howe, L. Silvati, and D. S. Barber, "Field study of noise-induced sleep disturbance," Journal of the Acoustical Society of America, vol. 98, no. 2, pp. 1025-1033, 1995.

[80] E. Öhrström, "Longitudinal surveys on effects of changes in road traffic noise-annoyance, activity disturbances, and psycho-social well-being," The Journal of the Acoustical Society of America, vol. 115, no. 2, pp. 719-729, 2004.

[81] S. Fidell, K. Pearsons, B. G. Tabachnick, and R. Howe, "Effects on sleep disturbance of changes in aircraft noise near three airports," Journal of the Acoustical Society of America, vol. 107, no. 5, pp. 2535-2547, 2000.

[82] J. A. Horne, F. L. Pankhurst, L. A. Reyner, K. Hume, and I. D. Diamond, "A field study of sleep disturbance: effects of aircraft noise and other factors on 5,742 nights of actimetrically monitored sleep in a large subject sample," Sleep, vol. 17, no. 2, pp. 146-159, 1994.

[83] D. S. Michaud, S. Fidell, K. Pearsons, K. C. Campbell, and S. E. Keith, "Review of field studies of aircraft noise-induced sleep disturbance," Journal of the Acoustical Society of America, vol. 121, no. 1, pp. 32-41, 2007.

[84] Y. Aydin and M. Kaltenbach, "Noise perception, heart rate and blood pressure in relation to aircraft noise in the vicinity of the Frankfurt airport," Clinical Research in Cardiology, vol. 96, no. 6, pp. 347-358, 2007.

[85] W. Dement and N. Kleitman, "Cyclic variations in EEG during sleep and their relation to eye movements, body motility, and dreaming," Electroencephalography and Clinical Neurophysiology, vol. 9, no. 4, pp. 673-690, 1957.

[86] B. Crüts, L. van Etten, H. Törnqvist et al., "Exposure to diesel exhaust induces changes in EEG in human volunteers," Particle and Fibre Toxicology, vol. 5, article no. 11, 2008.

[87] R. J. O. Davies, P. J. Belt, S. J. Roberts, N. J. Ali, and J. R. Stradling, "Arterial blood pressure responses to graded transient arousal from sleep in normal humans," Journal of Applied Physiology, vol. 74, no. 3, pp. 1123-1130, 1993.

[88] National Institute of Health, Air pollution and risk of incident hypertension and diabetes in U.S. black women, 2014, http:// projectreporter.nih.gov/project_info_description.cfm?aid= $8650890 \&$ icde $=22795915 \&$ ddparam $=\&$ ddvalue $=\&$ ddsub $=\&$ $\mathrm{cr}=2 \& \mathrm{csb}=$ default $\& \mathrm{cs}=$ ASC.

[89] W. Choi, S. Hu, M. He et al., "Neighborhood-scale air quality impacts of emissions from motor vehicles and aircraft," Atmospheric Environment, vol. 80, pp. 310-321, 2013.

[90] D. Houston, J. Wu, P. Ong, and A. Winer, "Structural disparities of urban traffic in Southern California: implications for vehiclerelated air pollution exposure in minority and high-poverty neighborhoods," Journal of Urban Affairs, vol. 26, no. 5, pp. 565592, 2004.

[91] N. P. Patel, M. A. Grandner, D. Xie, C. C. Branas, and N. Gooneratne, "Sleep disparity' in the population: poor sleep quality is strongly associated with poverty and ethnicity," $B M C$ Public Health, vol. 10, article 475, 2010.

[92] J. Whinnery, N. Jackson, P. Rattanaumpawan, and M. A. Grandner, "Short and long sleep duration associated with race/ ethnicity, sociodemographics, and Socioeconomic position," Sleep, vol. 37, no. 3, pp. 601-611, 2014.

[93] Y. Song, S. Ancoli-Israel, C. E. Lewis, S. Redline, S. L. Harrison, and K. L. Stone, "The association of race/ethnicity with objectively measured sleep characteristics in older men," Behavioral Sleep Medicine, vol. 10, no. 1, pp. 54-69, 2011.

[94] D. S. Lauderdale, K. L. Knutson, L. L. Yan et al., "Objectively measured sleep characteristics among early-middle-aged adults: the CARDIA study," The American Journal of Epidemiology, vol. 164, no. 1, pp. 5-16, 2006. 


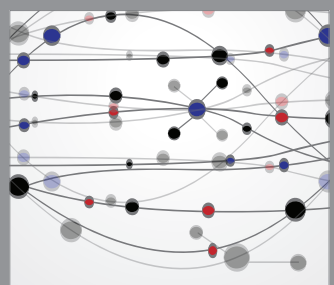

The Scientific World Journal
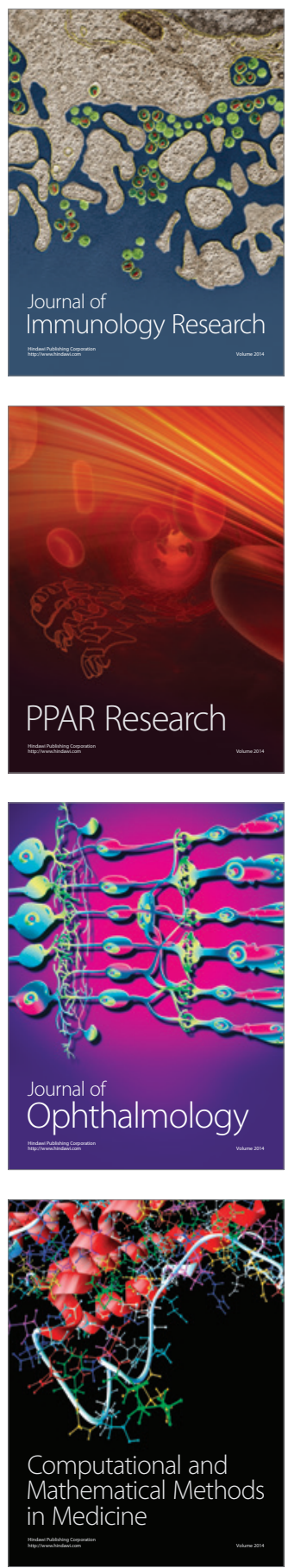

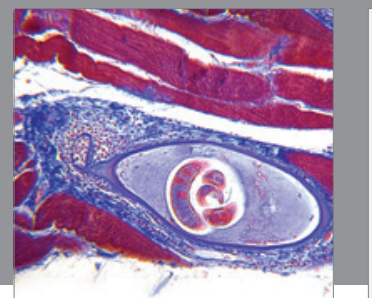

Gastroenterology

Research and Practice
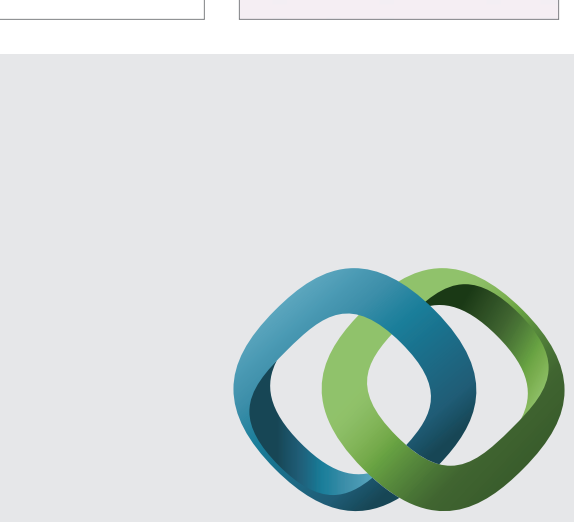

\section{Hindawi}

Submit your manuscripts at

http://www.hindawi.com
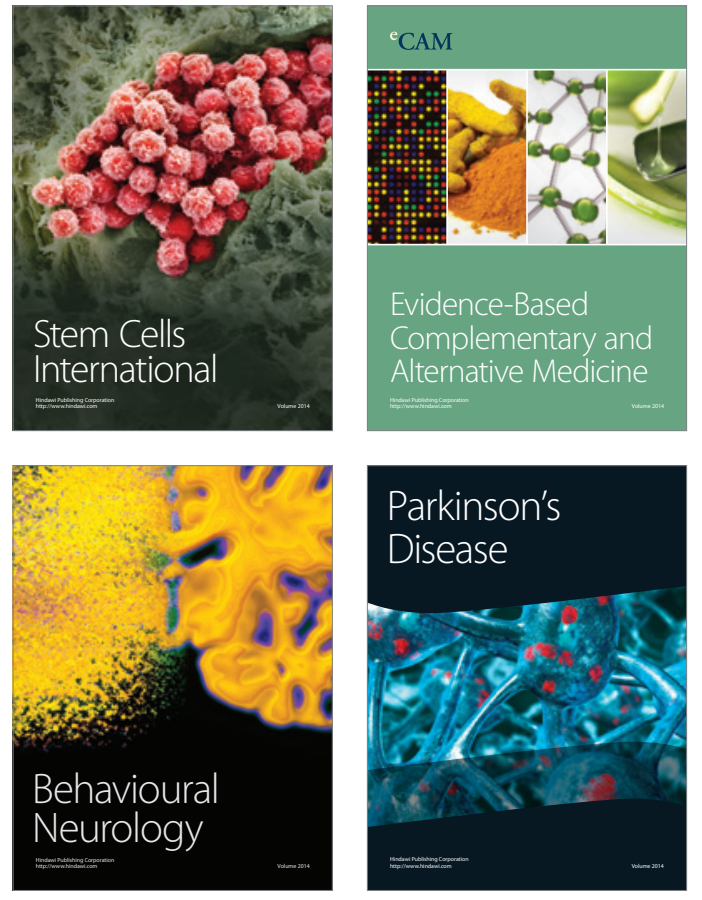
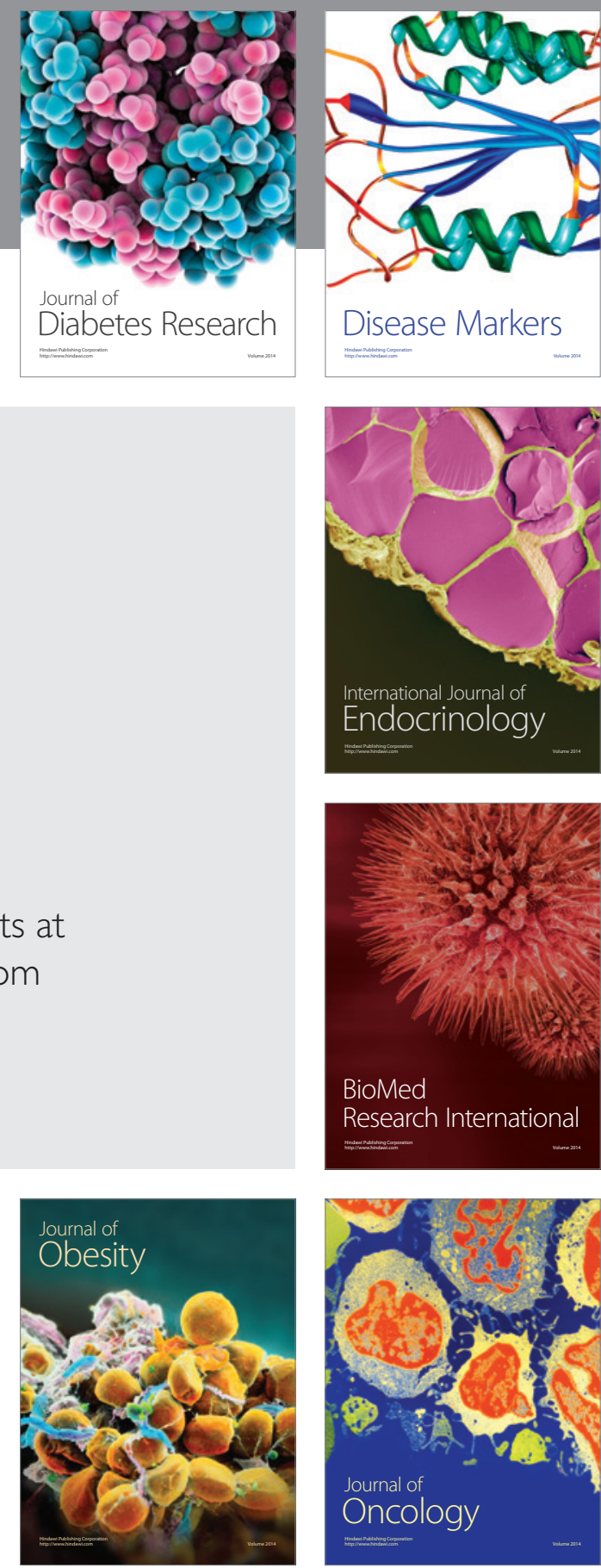

Disease Markers
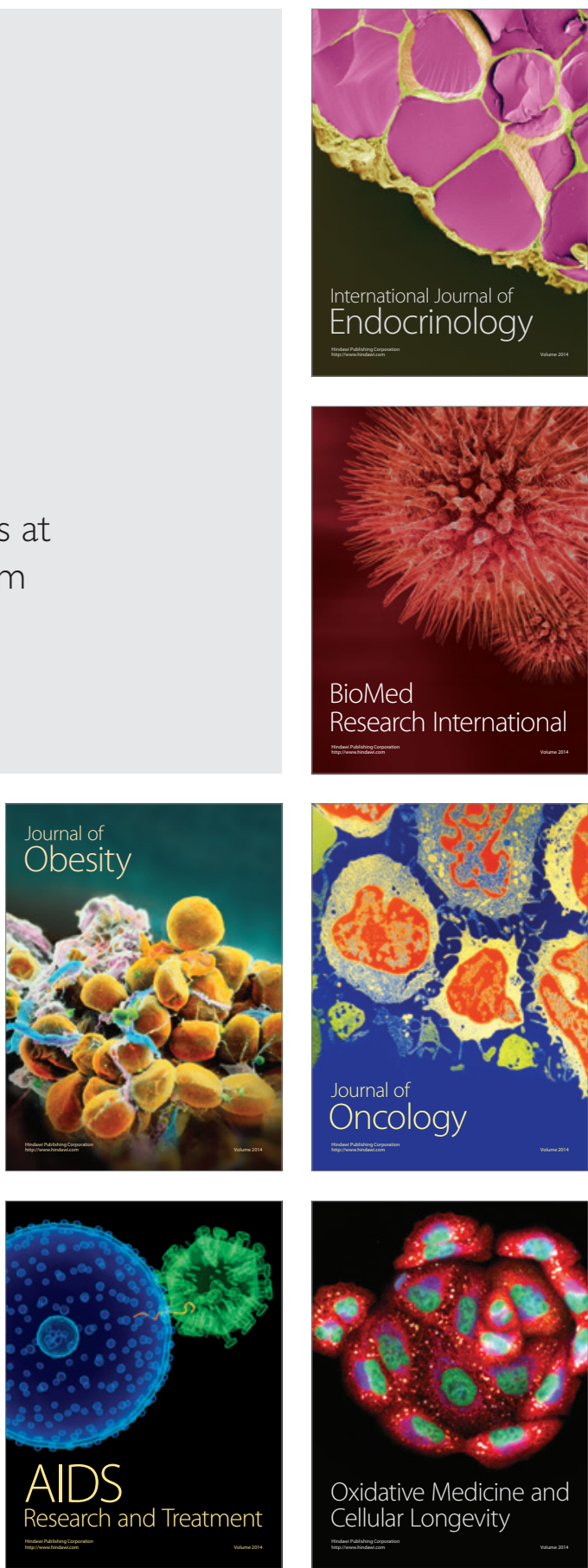